\title{
The Direction of Development for Archives of Plastic Surgery
}

\author{
Hye-Min Cho
}

Manuscript editor, Archives of Plastic Surgery

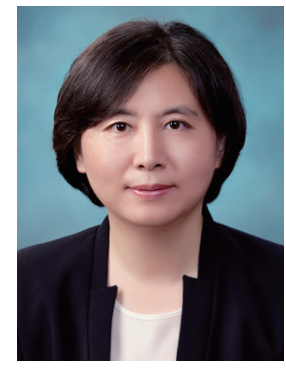

Archives of Plastic Surgery (APS) is the official journal of the Korean Society of Plastic and Reconstructive Surgeons (KSPRS). In 2012, KSPRS's Korean-language journal, Taehan Sŏnghyŏng Oekwa Hakhoe chi (Journal of the Korean Society of Plastic and Reconstructive Surgeons; ISSN, 1015-6402), was converted into an English-language journal and renamed APS. APS aims to be the leading forum for communication of surgical techniques related to the needs of Asian patients. APS also embraces its identity as the leading plastic surgery journal in Asia, aiming to become the main forum for communication among plastic surgery scholars and clinicians of the Asia-Pacific region and beyond, and the main voice presenting this group's technical innovations to an international audience. I consider myself lucky to be able to take part in the publication of this excellent academic journal, especially in the English journal publication project.

In July, at the request of the Editor-in-Chief to evaluate objectively and think seriously about the direction of development of APS, I spent some time thoroughly taking stock of the state of APS for the first time in a while. In just a year and a half after its launch, APS has been indexed in the major research databases, including KoreaMed, KoreaMed Synapse, PubMed, PubMed Central, Scopus, Embase, Chemical Abstract Service, EBSCO Host, Directory of Open Access Journals, and CrossRef. I consider this to be a good outcome achieved in just a short period of time.

In order to objectively evaluate APS, the evaluation was carried out using the Thomson Reuters Journal Selection Process [1] as a standard. As shown in Table 1, APS has fulfilled all of the basic publishing standards. In particular, it has comprised a variety of article types, such as editorials, review articles, original articles, case reports, ideas and innovations, letters, images, communications, continuing medical education (CME), and book reviews. On a few occasions, the description of Institutional Review Board approval and informed consent was omitted from the Methods section, suggesting the need to place more emphasis on publication ethics.

In order to evaluate the editorial content, I examined the surgery-related academic journals of different nations included in Journal Citation Reports (JCR). There were 189 academic journals that pertained to the field of surgery. Within Asia, Japan and Korea had two journals each, and India and Singapore each had one journal included in JCR. All together, they accounted for only $3 \%$ of the 189 journals dealing with surgery. Furthermore, when restricted to plastic surgery, JCR included no journals originating from Asia. There is a need for clinical journals that take Asian characteristics into consideration, and in that sense, I believe that APS has an important role to play.

The current state of international diversity is depicted in Table 2. Though $87 \%$ of the papers published in APS are from Korean authors, $65 \%$ of the authors that read and cite the papers included in APS are non-Korean. It is clear that APS is being widely used internationally.

The weakest point for APS is its citation rates. When we looked at citations of APS from the Web of Science, there were only 17 citations, and 60 citations in Scopus. The low number of citations is due to the fact that only a year and six months have passed since the conversion to an English journal, which is not enough time for papers that would cite APS to be published.

The APS citation rates were also analyzed according to the 
Table 1. Thomson Reuters' evaluation process and the current state of Archives of Plastic Surgery (APS)

\begin{tabular}{|c|c|c|}
\hline \multicolumn{2}{|r|}{ Thomson Reuters' evaluation process [1] } & APS \\
\hline \multicolumn{3}{|c|}{ Basic publishing standards } \\
\hline Timeliness & $\begin{array}{l}\text { A journal must be publishing according to its stated frequency to be considered for inclusion } \\
\text { in Web of Science. }\end{array}$ & Complies with publishing dates. \\
\hline $\begin{array}{l}\text { International } \\
\text { editorial } \\
\text { conventions }\end{array}$ & $\begin{array}{l}\text { These conventions include informative journal titles, fully descriptive article titles and author } \\
\text { abstracts, complete bibliographic information for all cited references, and full address } \\
\text { information for every author. }\end{array}$ & All information is provided. \\
\hline Full text English & Journals publish full text in English, or at very least, bibliographic information in English. & Full text in English \\
\hline Peer review & $\begin{array}{l}\text { The peer-review process signifies overall quality of the research presented and the } \\
\text { completeness of cited references. Inclusion of funding acknowledgements is also strongly } \\
\text { recommended. }\end{array}$ & $\begin{array}{l}\text { Peer-review process is complied with. It would be good } \\
\text { to include more papers that receive research funding. }\end{array}$ \\
\hline Editorial content & $\begin{array}{l}\text { Thomson Reuters editors determine if the content of a journal under evaluation will enrich } \\
\text { the database or if the topic is already adequately addressed in existing coverage. }\end{array}$ & $\begin{array}{l}\text { There is no other general plastic surgery journal in Asia. } \\
\text { APS has much to contribute. }\end{array}$ \\
\hline International diversity & $\begin{array}{l}\text { Thomson Reuters editors look for international diversity among the journal's contributing } \\
\text { authors, editors, and editorial advisory board members. This is particularly important in } \\
\text { journals targeting an international audience. }\end{array}$ & $\begin{array}{l}\text { Currently, there are many Korean authors. After 2013, } \\
\text { the number of international authors will increase. }\end{array}$ \\
\hline Citation analysis & $\begin{array}{l}\text { Citation analysis takes place on at least two levels. } \\
\text { - Citations to the journal itself, as expressed by impact factor and/or total citations received. } \\
\text { - In new journals that do not yet have a citation history at the publication level, analysts } \\
\text { examine the citation record of the contributing authors and editorial board members. }\end{array}$ & $\begin{array}{l}\text { Citations to APS are low. However, given the conversion } \\
\text { to an English-language journal and open-access, we } \\
\text { expect an increase. }\end{array}$ \\
\hline
\end{tabular}

Table 2. Archives of Plastic Surgery's internationalization

\begin{tabular}{|c|c|c|}
\hline Variable & Korea & Other countries \\
\hline Editorial board members & $23(61)$ & $15(39)$ \\
\hline Authors ${ }^{\text {a) }}$ & $178(87)$ & $27(13)$ \\
\hline Citations $s^{\text {b) }}$ & $16(35)$ & $30(65)$ \\
\hline \multicolumn{3}{|c|}{$\begin{array}{l}\text { Values are presented as number (\%). } \\
\text { a)The nationality of corresponding authors in Archives of Plastic Surgery fron } \\
\text { Volume 39, Issue } 1,2012 \text { to Volume } 40 \text {, Issue } 3,2013 \text {; }{ }^{\text {bS Scopus search result }} \\
\text { (search criteria for July } 8,2013 \text { ). }\end{array}$} \\
\hline
\end{tabular}

publication type (Table 3 ). The type that seemed to be cited the most was the review article with a citation rate of $110 \%$. The citation rates of case reports and special topic papers were $50 \%$ for each, and those of editorials and original articles were 33\% and $32 \%$, respectively. In general, case reports are cited less frequently than original articles $[2,3]$, but the citation rate of case reports was higher for APS, which can be attributed to the characteristics of the plastic surgery field. Recently, there has been a trend toward including fewer case reports in academic journals, but I believe that the inclusion of a variety of good cases would benefit readers.

For APS to develop even further, it would behoove us to refer to the research of Chew et al. [4]. In their study, Chew et al. [4] recommended the active recruitment of good papers that could receive many citations as a method for obtaining more citations. Examples of good papers that would be expected to be cited often are good systematic reviews and meta-analyses. They also advised improving services for authors, a representative example being minimizing the time it takes for reviewing and publishing.

\begin{tabular}{lccr|}
\hline \multicolumn{3}{l}{ Table 3. Citation rates by APS publication type } \\
\hline Publication type & No. of articles & No. of citations & $\%$ \\
\hline Editorial & 9 & 3 & 33 \\
Review article & 10 & 11 & 110 \\
Original article & 89 & 28 & 32 \\
Case report & 20 & 10 & 50 \\
Idea & 10 & 1 & 10 \\
Letter to the editor & 9 & 2 & 22 \\
Image & 43 & 2 & 5 \\
Communication & 5 & - & 0 \\
Continuing medical education & 3 & 1 & 33 \\
Book review & 3 & - & 0 \\
Special topic & 4 & 2 & 50 \\
Total & 205 & 60 & 29
\end{tabular}

Compiled using results cited in Scopus for papers published in Archives of Plastic Surgery (APS) Volume 39, Issue 1, 2012 to Volume 40, Issue 3, 2013 (search criteria for July 8,2013$)$.

Reducing the time it takes to publish papers could be helpful in attracting even better papers.

In addition, I also believe that we need active cooperation with associations from the Asia-Pacific region to make APS a plastic surgery journal that represents Asia. When the Journal of $G y$ necologic Oncology, put out by the Korean Society of Gynecologic Oncology, was chosen to become the official journal of the Asian Society of Gynecologic Oncology, it gained the interest of various nations in the Asia-Pacific region.

In light of all this, based on the current state and direction of development of APS, I look forward to what APS can be expected to achieve in the near future. 


\section{REFERENCES}

1. Testa J. The Thomson Reuters journal selection process [Internet]. New York: Thomson Reuters; 2012 [cited 2013 Aug 15]. Available from: http://wokinfo.com/essays/ journal-selection-process/.

2. Huh S. Citation analysis of the Korean Journal of Urology from Web of Science, Scopus, Korean Medical Citation Index, KoreaMed Synapse, and Google Scholar. Korean J Urol 2013;54:220-8.

3. Huh S. Citation analysis of The Korean Journal of Internal Medicine from KoMCI, Web of Science, and Scopus. Korean J Intern Med 2011;26:1-7.
4. Chew M, Villanueva EV, Van Der Weyden MB. Life and times of the impact factor: retrospective analysis of trends for seven medical journals (1994-2005) and their Editors' views. J R Soc Med 2007;100:142-50.

Correspondence: Hye-Min Cho

Infolumi, 210-202, 421 Pangyo-ro, Bundang-gu, Seongnam 463-926, Korea

Tel: +82-70-8839-8800, E-mail: infolumi.cho@gmail.com

No potential conflict of interest relevant to this article was reported.

Received: 21 Aug $2013 \bullet$ Revised: 21 Aug 2013 • Accepted: 21 Aug 2013 pISSN: 2234-6163・ elSSN: 2234-6171

http://dx.doi.org/10.5999/aps.2013.40.5.483 • Arch Plast Surg 2013;40:483-485 